\title{
The Impact of Economy, Policy, and Medical Care on the COVID-19 Epidemic
}

\author{
Wang Zhili", Yang Qingqing
}

College of Applied Mathematics, Chengdu University of Information Technology, Chengdu 610225, Sichuan, P.R. China

DOI: $\underline{10.36347 / \text { sipms.2020.v07i09.001 }}$

| Received: 30.08 .2020 | Accepted: 07.09.2020 | Published: 09.09.2020

*Corresponding author: Wang Zhili

Abstract

Review Article

At present, the new type of coronavirus (COVID-2019) has become a pandemic infectious disease in the world, which has caused a huge impact on the economy, people's lives, lives and property of all countries in the world. However, due to the different economic conditions and systems of various countries in the world, coupled with the inadequacy of testing equipment and personal protective equipment in many countries, the roads to fight the epidemic are different. To this end, a correlation analysis model based on economy, policy, medical treatment and the severity of the COVID19 epidemic was constructed, and the calculation results of several correlation analysis models were compared to explore the impact of economy, policy, and medical treatment on the severity of the COVID-19 epidemic. The results show that the H-convex correlation is more suitable for the study of this problem. The impact of economy, policy, and medical treatment on the severity of the COVID-19 epidemic is negatively correlated, and the impact of the policy has reached -0.861 .

Keywords: Impact of Economy COVID-19 Epidemic.

Copyright @ 2020: This is an open-access article distributed under the terms of the Creative Commons Attribution license which permits unrestricted use, distribution, and reproduction in any medium for non-commercial use (NonCommercial, or CC-BY-NC) provided the original author and source are credited.

\section{INTRODUCTION}

As the COVID-19 epidemic (COVID-19) spreads across the world in late 2019, the high infectivity and widespread nature of the virus make this battle difficult. This outbreak is the most serious global crisis since the end of the Cold War. It is also the first truly "globalized epidemic". Although the post-coVID19 world is unlikely to be fundamentally and radically different, the epidemic has a significant impact on the world economy, security and global development, and will accelerate the evolution of the international order and the face of human society. Some countries have seen the light at the end of the tunnel, while others still have a long way to go. In order to further prevent and control coVID-19, it is extremely important to explore the impact of economic level, national policy and medical level on the severity of coVID-19.Grey system theory is a new uncertainty research method proposed by Professor Deng Yulong of Huazhong University of Science and Technology in China. In 1982, Mr Deng julong journal System \& Control Letter "on the published an article called" Control Problem ofGrey System "of the paper [1], in the same year also published in the journal of huazhong institute of technology for the first gray System in Chinese papers one by one the grey Control System [2], two papers in this groundbreaking puts forward the concept of" grey System ", marks the birth of the grey System theory [3]. Grey system theory is a new type of uncertainty research method aiming at the problem of "few data and poor information". It takes the uncertain system with "part information known, part information unknown" as the research object. This method mainly generates the extracted value information through the development of known information, and then realizes the correct description and effective monitoring of the uncertain system. Therefore, it can effectively solve the uncertainty problem of the relationship between data and the original data [4,5]. Grey correlation is an important branch of grey system theory. The basic idea is to use the sequence of linear interpolation between adjacent points on discrete data mapping the geometry in space, and then through the connection between sequence of geometric feature discriminant sequence is closely [6] in statistical theory, judge the relationship between variables must first clear relationship of function features, such as linear or nonlinear relationship, so the statistical methods must be a large number of samples to support [7]. In the grey correlation theory, "grey" is mainly reflected in the uncertainty of the relationship between data, which may be manifested as proximity, similarity, amplitude or 
period, or as a mixture of several kinds of relationships. Although this uncertainty relationship makes the model lose some "accuracy", it also makes the model still applicable in the case of small samples, which effectively expands the scope of application of the model. Therefore, the grey correlation model shows great vitality. The study of this problem (correlation analysis of economy, policy, medical treatment and severity of COVID-19) will help us to have a more comprehensive and clear understanding of the epidemic.

Definition 1[8]: There is a sequence of system behavior

$$
X_{0}=\left\{x_{0}(1), x_{0}(2), \cdots, x_{0}(n)\right\}
$$

And has the system correlation sequence

$$
\begin{gathered}
X_{1}=\left\{x_{1}(1), x_{1}(2), \cdots, x_{1}(n)\right\} \\
X_{i}=\left\{x_{i}(1), x_{i}(2), \cdots, x_{i}(n)\right\} \\
X_{m}=\left\{x_{m}(1), x_{m}(2), \cdots, x_{m}(n)\right\}
\end{gathered}
$$

Among them, $i=1,2, \cdots, m$

$$
\gamma\left(x_{0}(k), x_{i}(k)\right)=\frac{\min _{i} \min _{k}\left|x_{0}(k)-x_{i}(k)\right|+\xi \max _{i} \max _{k}\left|x_{0}(k)-x_{i}(k)\right|}{\left|x_{0}(k)-x_{i}(k)\right|+\xi \max _{i} \max _{k}\left|x_{0}(k)-x_{i}(k)\right|}
$$

Is the correlation coefficient of gray points, where $\xi$ is the resolution coefficient, $\xi \in(0,1)$, called

$$
\text { 1.1.1. } \gamma\left(X_{0}, X_{i}\right)=\frac{1}{n} \sum_{k=1}^{n} \gamma\left(x_{0}(k), x_{i}(k)\right)
$$

Is the Dunn's gray correlation degree of sequence $X_{0}$ and $X_{i}$.

Based on similarity and proximity perspective of nelson's new grey correlation the relational model is divided into proximity and similarity to separate discussion, is advantageous for the research according to the type of things to choose the appropriate model, then changed the previous correlations to calculate the correlation coefficient between corresponding points, the data sequence as a whole, the correlation was calculated directly by using the integral.

Definition 2[9]: There is a sequence of system behavior $X_{i}=\left\{x_{i}(1), x_{i}(2), \cdots, x_{i}(n)\right\}, \quad X_{j}=\left(x_{j}(1), x_{j}(2), \cdots, x_{j}(n)\right)$, Where

$$
\begin{gathered}
X_{i}^{0}=\left(x_{i}(1)-x_{i}(1), x_{i}(2)-x_{i}(1), \cdots, x_{i}(n)-x_{i}(1)\right) \\
X_{j}{ }^{0}=\left(x_{j}(1)-x_{j}(1), x_{j}(2)-x_{j}(1), \cdots, x_{j}(n)-x_{j}(1)\right)
\end{gathered}
$$

Let

$$
\begin{gathered}
s_{i}-s_{j}=\int_{1}^{n}\left(X_{i}{ }^{0}-X_{j}{ }^{0}\right) \\
S_{i}-S_{j}=\int_{1}^{n}\left(X_{i}-X_{j}\right)
\end{gathered}
$$

Said

$$
\varepsilon_{i j}=\frac{1}{1+\left|s_{i}-s_{j}\right|}
$$


Refers to the grey relational degree based on the similarity perspective, and denotes

$$
\rho_{i j}=\frac{1}{1+\left|S_{i}-S_{j}\right|}
$$

Refers to the grey relational degree based on proximity perspective, namely the absolute relational degree.
Definition 3[10]: For the dispersion system, the row is three adjacent Numbers $(x(k), x(k+1)$, $x(k+2))$ in sequence $X$.The approximate calculated value of h-convexity of sequence $X$ at $t=k+1$ is obtained by forming a broken line $\mathrm{ABC}$, which is called H-convexity, denoted by $\hat{d}_{H}(X, k+1)$ and denoted by $\hat{d}_{H}$, where

According to

$$
\hat{d}_{H}(X, k+1)=\frac{x(k+1)-\frac{x(k)+x(k+2)}{2}}{\sqrt{4+[x(k+2)-x(k)]^{2}}}
$$

$$
\hat{\gamma}_{H\left(X_{0}, X_{i}\right)}(k)=\operatorname{sgn}\left(\hat{d}_{H}\left(X_{0}, k\right), \hat{d}_{H}\left(X_{i}, k\right)\right)=\frac{1}{1+|| \hat{d}_{H}\left(X_{0}, k\right)\left|-\hat{d}_{H}\left(X_{i}, k\right)\right|}
$$

According to AIs the coefficient of H-convex correlation degree. Where, $\operatorname{sgn}(\bullet)$ is a sign function

$$
\operatorname{sgn}(x)=\left\{\begin{array}{c}
1, x>0 \\
0, x=0 \\
-1, x<0
\end{array}\right.
$$

$$
\hat{R}_{H}\left(X_{0}, X_{i}\right)=\frac{1}{n-2} \sum_{k=2}^{n-1} \hat{\gamma}_{H\left(X_{0}, X_{i}\right)}(k)
$$

It is called h-convex correlation.

The grey relational model calculation formula is analyzed, and the classic grey relational model with correlation coefficient and h-convex relational degree are summarized as shown in Table 4.1:

Table-1: Summary of classic grey relational model

\begin{tabular}{|c|c|c|c|c|}
\hline & Grey relational coefficient & variable & $\begin{array}{c}\text { Variable } \\
\text { value range }\end{array}$ & $\begin{array}{c}\text { The range of } \\
\text { correlation coefficient }\end{array}$ \\
\hline $\begin{array}{c}\text { Dunn's } \\
\text { correlation }\end{array}$ & $\gamma_{i j}(k)=\frac{m+\xi M}{\left|x_{i}(k)-x_{j}(k)\right|+\xi M}$ & $\left|x_{i}(k)-x_{j}(k)\right|$ & {$[m, M]$} & {$\left[\frac{m+\xi M}{(1+\xi) M}\right]$} \\
\hline $\begin{array}{c}\text { Absolute } \\
\text { correlation }\end{array}$ & $\varepsilon_{i j}=\frac{1}{1+\left|s_{i}-s_{j}\right|}$ & $\left|s_{i}-s_{j}\right|$ & {$[0,+\infty)$} & $(0,1]$ \\
\hline $\begin{array}{c}\text { H- Convex } \\
\text { correlation }\end{array}$ & $\hat{\gamma}_{H\left(X_{0}, X_{i}\right)}(k)$ & $\operatorname{sgn} \bullet\left|\hat{d}_{H}\left(X_{0}\right)\right|-\mid \hat{d}_{H}\left(X_{i}\right) \|_{k}$ & $(-\infty,+\infty)$ & {$[-1,1]$} \\
\hline
\end{tabular}

\section{DATA PREPROCESSING}

All statistical analysis is based on data, and analysis without data is meaningless. Therefore, before the formal solution of the problem, the data should be analyzed and preprocessed by the corresponding mathematical method, which is helpful for the establishment and solution of subsequent models. Economic level, national policy, medical level and epidemic severity are qualitative indicators, which need to be quantified. This paper chooses the value of GDP to represent the economy; the number of government reports and policies enacted in response to the COVID19 epidemic is presented in a ratio of 2 to 8 . The medical level is represented by the value of the number of medical beds; the severity index indicates the severity of the epidemic. Since economic, policy, medical, and COVID-19 severity are different dimensions, we need to normalize them, and z-Score is standardized in this selection.

This method is based on the original data's mean $\bar{x}$ (Mean) and standard deviation $u$ (Standard deviation) to standardize the data. The original value $A$ of $X$ is standardized to $X^{\prime}$ by using $Z$-score, and its formula is:

$$
X^{\prime}=\frac{X-\bar{x}}{u}
$$

\section{MODEL SOLVING}

Through calculation, the results are shown in Table 
Table-2: Results of grey correlation analysis

\begin{tabular}{|c|c|c|c|}
\hline & $\begin{array}{c}\text { Dunn's } \\
\text { correlation }\end{array}$ & $\begin{array}{c}\text { Absolute } \\
\text { correlation }\end{array}$ & $\begin{array}{c}\text { H- Convex } \\
\text { correlation }\end{array}$ \\
\hline Economic level and severity of the epidemic & 0.236 & 0.176 & -0.631 \\
\hline National policy and severity of the epidemic & 0.063 & 0.054 & -0.861 \\
\hline The level of medical care and the severity of the epidemic & 0.251 & 0.194 & -0.773 \\
\hline
\end{tabular}

\section{We can see from Table 2 that:}

(1) H-convex correlation is more suitable as a correlation analysis model to analyze the severity of the economic, policy, medical and COVID-19 epidemic. The correlation degree calculated by Deng's correlation degree and absolute correlation degree reflects that the economic level is positively correlated with the severity of the epidemic, the national policy is positively correlated with the severity of the epidemic, and the medical level is positively correlated with the severity of the epidemic, that is, the higher the economic level, the better the national policy and the better the medical level, while the epidemic level is serious. It doesn't make sense. The correlation degree calculated by the $\mathrm{H}$ convex correlation degree reflects that the economic level is negatively correlated with the severity of the epidemic, the national policy is negatively correlated with the severity of the epidemic, and the medical level is negatively correlated with the severity of the epidemic, that is, the higher the economic level, the better the national policy, and the better the medical level, while the epidemic level is serious. It makes more sense.

(2) Economy, policy and medical treatment all affect the severity of COVID-19 epidemic and are negatively correlated, that is, the higher the economic level, the better the national policy and the better the medical level and the epidemic is serious. Among them, the influence of national policy is the most serious, with the correlation degree reaching -0.861 .

\section{CONCLUSION}

The highly infectious and widespread nature of the COVID-19 epidemic has made this war without a bomb difficult, bringing the world's worst sudden crisis. It affects the economy of all countries in the world, the lives of all peoples in the world, the lives and property of all countries in the world, etc. However, due to the different economic conditions and systems in different countries around the world, as well as the lack of testing equipment and personal protective equipment in many countries, the way to fight the epidemic varies. Some countries have seen the light at the end of the tunnel, while others still have a long way to go. In order to further prevent and control coVID-19, this paper established multiple correlation analysis models to explore the impact of economic level, national policies and medical level on the severity of COVID-19 epidemic. Through comparison with reality, it was found that h-convex correlation was more suitable to be used as a correlation analysis model to analyze the severity of coVID-19 epidemic. Under the h-convex correlation analysis model, the economic level is negatively correlated with the severity of the epidemic, the national policies are negatively correlated with the severity of the epidemic, and the medical level is negatively correlated with the severity of the epidemic, namely, the higher the economic level, the better the national policies and the better the medical level, while the epidemic level is serious. Among them, the influence of national policy is the most serious, with the correlation degree reaching -0.861 . This also for the current epidemic severity index in the top 10 countries (the United States, Colombia, Peru, Bangladesh, Brazil, India, Honduras, Spain, Britain, Bolivia) provide effective references, among them, the United States as an economic superpower, top medical treatment level, should be extremely importance to the promulgation of the national defense policy.

\section{REFERENCES}

1. Deng J L. Control problems of grey systems $[\mathrm{J}]$. Systems\&Control Letters. 1982, 1(5):288-294.

2. Deng Julong. Grey Control System [J]. Journal of Huazhong University of Science and Technology (Natural Science edition). 1982(03):9-18.

3. Deng Julong. Grey Theory Basis [M] Huazhong University of Science and Technology Press; 2002.

4. Liu Sifeng, Dangyao-Guo, Fang Zhi-geng. Grey system Theory and its Application [M]. 5th Ed. Beijing: Science Press; 2010.

5. Liu S F, Lin Y. Grey Systems: Theory and Applications [M]. 2010.

6. Jin Y.Grey Incidence Analysis on Sort Standard of National Standard [J]. Cancer Cell International, 2013, 13(1):77-77.

7. Ye j. fzzy decision-making method based on the weighted correlation coefficient under intuitionistic fuzzy environment [J].European Journal of Operational Research. 2010,205(1): 202-204.

8. Liu Sifeng, Xie Naiming. Grey System Theory and Its Application (6th edition)[M]. Beijing: Science Press; 2016.

9. Liu Sifeng, Xie Naiming. A new grey relational analysis model based on similarity and proximity. System Engineering Theory and Practice [J].2010, 30(5): 881-887.

10. Pan Pingguo, Chen Yongming, Xie Haiying. [J]. Statistics and Decision-making. 2016(09): 31-34. 